\title{
Applicability of a Progesterone-Based Timed Artificilal Insemination Protocol after Follicular Fluid Aspiration Using the Ovum Pick-up Technique in Suckled Beef Cows
}

\author{
Toh-Ichi HIRATA ${ }^{1)}$, Toshinori HOSHINA ${ }^{1)}$, Shu-Ichi SASAKI ${ }^{1)}$, Osamu SASAKI') \\ and Takeshi OSAWA ${ }^{1)}$
}

${ }^{1)}$ Faculty of Agriculture, Iwate University, Morioka 020-8550, Japan

\begin{abstract}
We conducted a progesterone-based timed AI protocol after follicular fluid aspiration using the ovum pick-up (OPU) technique to examine its applicability to the suckled beef cow. A total of 19 beef cows were randomly allocated to one of the following three groups based on the number of days postpartum: 13 to 60 days (Group A: suckled; early postpartum period, n=9), 61 to 150 days (Group B: suckled; mid postpartum period, $\mathrm{n}=6$ ), or 151 to 281 days (Group C: non-suckled; prolonged open period, $n=4)$ postpartum. These cows were treated with follicular fluid aspiration and insertion of a progesterone-releasing intravaginal device (PRID) on day 0 . The PRID was removed and $500 \mu \mathrm{g}$ of cloprostenol was intramuscularly administered on day 7. A dose (100 $\mu \mathrm{g})$ of fertirelin acetate was injected intramuscularly 48 hours later, and this was followed by a timed AI (TAI) after another 18 hours (day 10). Serum samples were taken on days $0,7,9,10,12,17,24$ and 31 for determination of the estradiol-17 $\beta\left(\mathrm{E}_{2}\right)$ and progesterone concentrations. Pregnancy diagnosis was made by rectal palpation approximately 60 days after TAI. There was no significant difference in the peripheral $\mathrm{E}_{2}$ concentrations among the three groups during the period of the hormonal treatment. The average progesterone concentrations in Group A on day 17 were significantly higher than those in Group B and exceeded $1.0 \mathrm{ng} / \mathrm{ml}$ on day 17 and thereafter. There was no significant difference in the numbers of collected immature oocytes among the three groups. The pregnancy rates in Groups A, B, and C were $77.8 \%(7 / 9), 83.3 \%(5 / 6)$ and $50.0 \%(2 / 4)$, respectively. In conclusion, this timed AI protocol is applicable to suckled beef cows within the period of 60 days postpartum.

Key words: Follicular fluid aspiration, Progesterone-releasing intravaginal device (PRID), Suckled beef cow, Timed artificial insemination
\end{abstract}

(J. Reprod. Dev. 53: 171-177, 2007)

A model for induction of ovulation and initiation of cyclicity using an intravaginal progesteronereleasing device in anestrous early postpartum suckled beef cows has been recently proposed [13]. Yavas et al. [4] demonstrated that insertion of a progesterone-releasing intravaginal devise (PRID) for 10 days into the vagina of 21-day postpartum beef cows allowed the dominant follicle to undergo

Accepted for publication: September 29, 2006

Published online: November 1, 2006

Correspondence: T. Osawa (e-mail: osawa@iwate-u.ac.jp) terminal maturation; an LH surge; ovulation; a normal lifespan and function for the CL; and continued cyclicity in 50 to $60 \%$ of the cows. Use of an intravaginal progesterone-releasing device in protocols for ovulation synchronization and timed artificial insemination (TAI) has been reported to be effective for increasing conception rate [5-13]. Application of this protocol (PRID + TAI) could shorten the calving interval and have notable economic effects. Estradiol benzoate in PRIDs elevates plasma estradiol-17 $\beta\left(\mathrm{E}_{2}\right)$ concentrations 
for two days after insertion, and this high $E_{2}$ environment helps in synchronization of follicular waves [14]. Follicular aspiration by ovum pick-up (OPU) before insertion of a PRID could omit the phase of follicular degeneration and synchronize the emergence of follicular waves without large individual variations [15-17]. This procedure would also be useful in collecting valuable embryos without prolonging the open period of the donor cow. The objective of this study was to clarify the applicability of a progesterone (PRID)-based TAI protocol after follicular fluid aspiration using the OPU technique in early postpartum suckled beef cows.

\section{Materials and Methods}

\section{Animals}

A total of 19 beef cows (16 Japanese Black cows and 3 Japanese Short Horn cows) kept at the Omyojin Experimental Station, Iwate University, were used at 13 to 281 days postpartum. The ages, parities and body weights (mean \pm SD) of these animals were $51.4 \pm 22.8$ months, $2.6 \pm 1.6$ and 411.3 $\pm 70.9 \mathrm{~kg}$, respectively (Table 1 ). The animals were suckled by calves until weaning at 150 days postpartum.

\section{Timed AI protocol}

The 19 cows were randomly allocated to one of the following three groups based on the number of days postpartum at the time of OPU: 13 to 60 days postpartum (Group A: suckled; early postpartum period, $\mathrm{n}=9$ ), 61 to 150 days (Group B: suckled; mid postpartum period, $\mathrm{n}=6$ ), or 151 to 281 days (Group C: non-suckled; prolonged open period, $\mathrm{n}=4$ ). These cows were treated with OPU on day 0 and fitted with a PRID (containing $1.55 \mathrm{~g}$ of progesterone and an estradiol benzoate capsule containing $10 \mathrm{mg}$ of estradiol benzoate; Aska Pharmaceutical Co., Ltd., Tokyo, Japan) immediately after. The device was left in the animals for 7 days, and $500 \mu \mathrm{g}$ of cloprostenol, a prostaglandin $\mathrm{F}_{2 \alpha}$ analog (Estrumate, Nagase Medicals, Itami, Japan), was administered intramuscularly on day 7 at the removal of the device. A dose $(100 \mu \mathrm{g})$ of fertirelin acetate, a GnRH analog (Conceral; Nagase Medicals), was injected intramuscularly on day 9 ( $48 \mathrm{~h}$ after the prostaglandin injection), and this was followed by a timed AI (TAI) 18 to $19 \mathrm{~h}$ later (day 10). Palpation per rectum was performed on days $0,7,9,10,12,17$, 24 and 31 to monitor ovarian status. Pregnancy diagnosis was made approximately 60 days after TAI by rectal palpation. Blood samples were taken from jugular veins on days $0,7,9,10,12,17,24$ and 31. Each blood sample was incubated at $37 \mathrm{C}$ for 2 $\mathrm{h}$ immediately after collection, and the serum was separated by centrifugation at $700 \mathrm{~g}$ for $15 \mathrm{~min}$. The serum samples were then stored at $-20 \mathrm{C}$ until hormone assays were performed.

\section{Ovum pick-up}

All cows were restrained in standing stocks, sedated with $0.04 \mathrm{mg} / \mathrm{kg}$ BW xylazine (Celactal; Bayer Medical, Tokyo, Japan), administered intramuscularly, and treated with antispasmodic prifinium bromide $(75 \mathrm{mg} /$ head intravenously; Taiyo Yakuhin Co., Ltd., Nagoya, Japan) in order to decrease rectal peristalsis. Immature oocytes of follicles $3 \mathrm{~mm}$ or greater in diameter were harvested from the animals using an ultrasoundguided transvaginal aspiration system (SSD-900 ultrasonograph, UST-M15-21079 probe; Aloka, Tokyo, Japan) equipped with disposable 17-G single-lumen, sterile needles. The collected immature oocytes were examined under a microscope, and those high-keyed and surrounded by more than three layers of dense cumulus cells with a diameter of approximately $120 \mu \mathrm{m}$ were considered to be culture-competent oocytes.

\section{Hormone assays}

Serum concentrations of progesterone and $E_{2}$ were determined by radioimmunoassay [18]. Ovine antisera raised against progesterone, GDN\#337, and against estradiol-17 $\beta$, GDN\#244, were provided by Dr. G. D. Niswender (Colorado State University, Fort Collins, CO, USA). The intraand interassay coefficients of variation were 9.3 and $7.6 \%$ for progesterone and 7.0 and $12.7 \%$ for $E_{2}$, respectively.

\section{Statistical analyses}

One-way analysis of variance and Dunn's test were used to determine differences in hormonal concentrations, number of collected oocytes, and number of culture-competent oocytes among different groups. Conception rates and percentages of the culture-competent oocytes in the collected immature oocytes among the different groups were 
Table 1. Hormonal, ovarian, and pregnancy status of the postpartum beef cows

\begin{tabular}{|c|c|c|c|c|c|c|c|c|c|c|}
\hline Group $^{* 1}$ & Cow No. & Breed $^{* 2}$ & Parity & $\begin{array}{l}\text { Days } \\
\text { postpartum at } \\
\text { the onset of } \\
\text { treatment }\end{array}$ & $\begin{array}{l}\text { No. of AI } \\
\text { and ET at } \\
\text { the onset of } \\
\text { treatment }\end{array}$ & $\begin{array}{c}\text { Progesterone } \\
\text { concentrations at } \\
\text { PRID insertion } \\
(\mathrm{ng} / \mathrm{ml})\end{array}$ & $\begin{array}{l}\text { Peak estradiol } \\
-17 \beta \text { at } \mathrm{GnRH} \\
\text { injection }\end{array}$ & $\begin{array}{c}\text { Progesterone } \\
\text { concentrations at } \\
\text { PRID removal } \\
(\mathrm{ng} / \mathrm{ml})\end{array}$ & $\begin{array}{l}\text { Synchronized } \\
\text { ovulation*4 }\end{array}$ & Pregnancy $^{* 5}$ \\
\hline \multirow{9}{*}{$A(n=9)$} & 1 & B & 1 & 13 & 0 & 0.290 & 0 & 1.472 & 0 & + \\
\hline & 2 & B & 5 & 23 & 0 & $\mathrm{BML}^{* 6}$ & 0 & 0.376 & $\Lambda$ & + \\
\hline & 3 & B & 4 & 27 & 0 & 0.012 & 0 & 0.572 & 0 & + \\
\hline & 4 & B & 2 & 28 & 0 & 0.003 & $x$ & 0.413 & 0 & + \\
\hline & 5 & B & 1 & 29 & 0 & 0.028 & $x$ & 1.787 & 0 & + \\
\hline & 6 & $S$ & 2 & 30 & 0 & 0.001 & 0 & 0.812 & 0 & - \\
\hline & 7 & B & 4 & 38 & 0 & 0.879 & 0 & 2.473 & 0 & + \\
\hline & 8 & B & 2 & 46 & 0 & 0.018 & $\wedge$ & 1.763 & 0 & - \\
\hline & 9 & B & 3 & 49 & 0 & 0.020 & 0 & 0.933 & 0 & + \\
\hline \multirow{6}{*}{$B(n=6)$} & 10 & B & 1 & 84 & 0 & BML & $\wedge$ & 0.731 & 0 & + \\
\hline & 11 & B & 3 & 86 & 0 & 0.051 & 0 & 1.019 & 0 & + \\
\hline & 12 & B & 3 & 110 & 0 & 2.591 & 0 & 0.608 & 0 & + \\
\hline & 13 & B & 3 & 124 & 1 & 5.973 & 0 & 0.911 & 0 & + \\
\hline & 14 & B & 6 & 125 & 0 & 0.028 & 0 & 0.561 & 0 & - \\
\hline & 15 & B & 1 & 140 & 0 & 0.001 & $x$ & 0.305 & $\Lambda$ & + \\
\hline \multirow{4}{*}{$C(n=4)$} & 16 & $S$ & 1 & 157 & 3 & 4.608 & 0 & 1.751 & 0 & + \\
\hline & 17 & B & 5 & 170 & 1 & 2.122 & $x$ & 2.008 & $\wedge$ & $+{ }^{* 7}$ \\
\hline & 18 & B & 1 & 246 & 2 & 1.181 & $x$ & 0.969 & $x$ & - \\
\hline & 19 & $S$ & 1 & 281 & 1 & 0.003 & $x$ & 1.732 & $\wedge$ & - \\
\hline
\end{tabular}

*1: The animals were treated at A (60 days or earlier), B (61 to 150 days) and C (151 days or later) postpartum.

*2: B (Japanese Black); S (Japanese Shorthorn).

*3: $\bigcirc(3 \mathrm{pg} / \mathrm{ml}$ or greater); $\wedge$ (less than $3 \mathrm{pg} / \mathrm{ml}) ; \times($ no peak observed).

*4: $\bigcirc$ (ovulated within two days after timed AI); $\wedge$ (a corpus luteum of at least $20 \mathrm{~mm}$ in diameter was observed within 21 days after timed AI); $\times$ (no ovulation).

*5: Pregnancy diagnosis was performed around 60 days after timed AI.

*6: Below measurable limits.

*7: Double ovulation.

compared using Fisher's exact probability test and the chi-square test, respectively. Differences were considered to be significant at $\mathrm{P}<0.05$. These analyses were performed using the StatView 4.0 software (Abacus Concepts, Berkeley, CA, USA).

\section{Results}

\section{Ovarian dynamics}

In 14 of the 19 cows (73.7\%), follicular growth was confirmed from the time of PRID removal to the time of GnRH analog injection and ovulation was confirmed within two days after TAI was performed (Table 1). In four of the other five animals, formation of a functional corpus luteum with a longitudinal diameter of $20 \mathrm{~mm}$ or greater was observed by 21 days after TAI. No corpus luteum was observed in the remaining animal. In one animal from Group C (Cow No. 17), two dominant follicles were ovulated, and consequently, two corpora lutea formed.

\section{Hormonal profiles}

The average peripheral $\mathrm{E}_{2}$ concentrations in the cows of Groups A and B decreased during PRID insertion and increased from the time of PRID removal to the time of GnRH injection (Fig. 1). On the other hand, those in the animals of Group C increased during PRID insertion and decreased from PRID removal to AI. The peripheral $E_{2}$ concentrations decreased to $2 \mathrm{pg} / \mathrm{ml}$ or lower on the day of ovulation in all the groups. There was no significant difference in the peripheral $E_{2}$ concentrations among the three groups during the hormonal treatment period.

At the time of PRID insertion (day 0), the peripheral concentrations of progesterone in the cows of Group A $(0.14 \mathrm{ng} / \mathrm{ml})$ were lower than those in the cows of Groups B $(1.44 \mathrm{ng} / \mathrm{ml})$ and C 


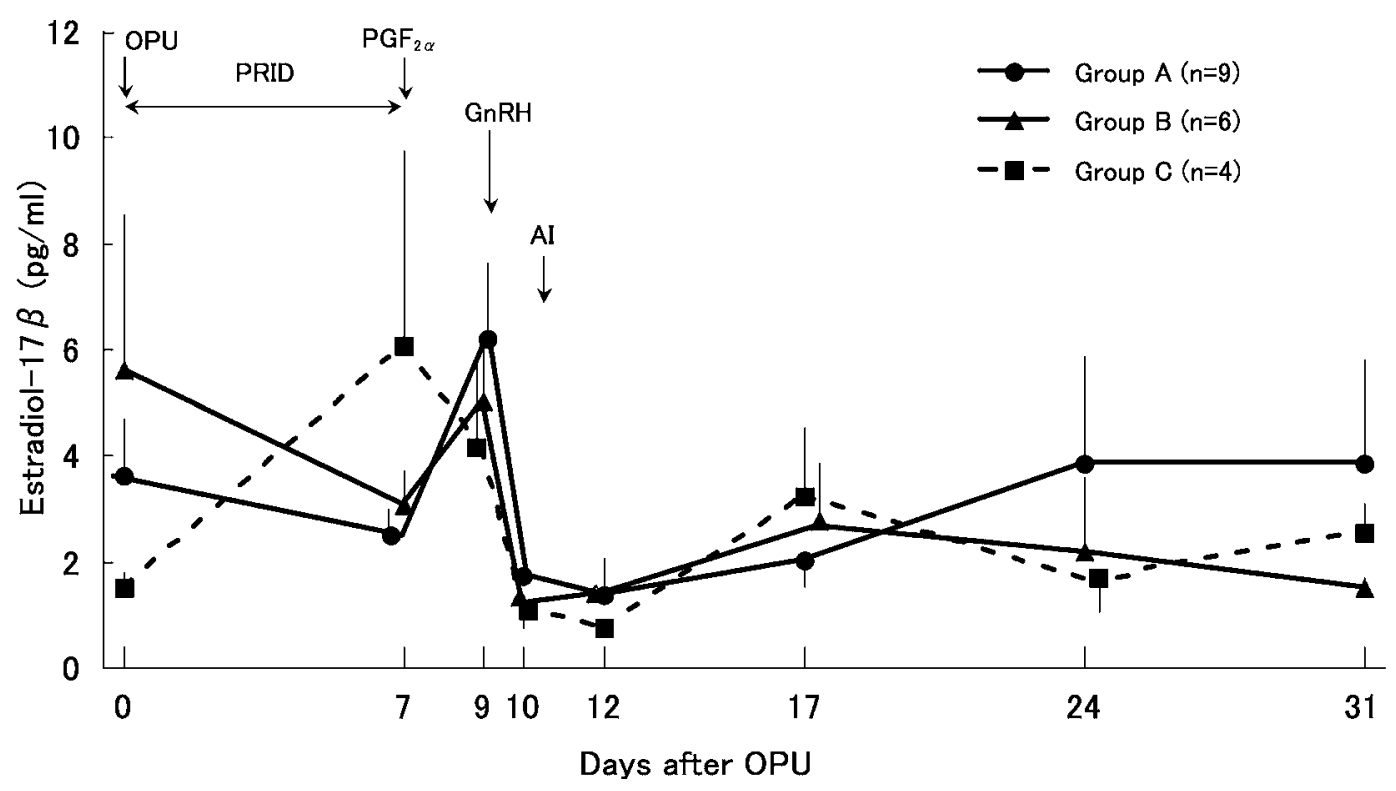

Fig. 1. Profile of the serum estradiol- $17 \beta$ concentrations (means \pm SEM) in the postpartum beef cows treated with a progesterone releasing intravaginal device (PRID)-based timed AI protocol after follicular fluid aspiration using ovum pick-up (OPU). Group A (early postpartum period): cows 13 to 60 days postpartum; Group B (mid postpartum period): cows 61 to 150 days postpartum; Group C (prolonged open period): 151 to 281 days postpartum.

$(1.98 \mathrm{ng} / \mathrm{ml})$ (Fig. 2). Progesterone concentrations decreased from the time of $\mathrm{PGF}_{2 \alpha}$ injection to the time of GnRH injection, remained low until the day of ovulation, and increased to $1.0 \mathrm{ng} / \mathrm{ml}$ or higher by day 24 in all the groups. The progesterone concentrations of Group A were significantly $(\mathrm{P}<0.01)$ higher than those of Group B on day 17.

\section{Conception rate}

The conception rates of Groups A, B, and C were $77.8(7 / 9), 83.3(5 / 6)$, and $50.0 \%(2 / 4)$, respectively (Table 1). Although no significant difference was found in conception rate among the three groups due to the small number of animals used in this study, the total conception rate of the suckled cows (combination of Groups A and B: 80.0\%, 12/15) was higher than that of the non-suckled animals (Group C: $50.0 \%, 2 / 4)$. Out of 11 cows showing $E_{2}$ concentrations of $3 \mathrm{pg} / \mathrm{ml}$ or greater at the time of GnRH injection, 10 animals (90.9\%) conceived. On the other hand, $3(37.5 \%)$ of 8 cows showing $E_{2}$ concentrations of less than $3 \mathrm{pg} / \mathrm{ml}$ at the time of $\mathrm{GnRH}$ injection conceived.

\section{OPU outcome}

The numbers of follicles aspirated by OPU in
Groups A, B, and C were 12.3 $\pm 2.4,15.7 \pm 4.2$ and $17.5 \pm 4.5$, respectively. The percentages of culturecompetent oocytes in the collected immature oocytes were $41.4,58.5$ and $61.4 \%$, respectively. No significant difference was detected in OPU outcome among the three groups (Table 2).

\section{Discussion}

Yavas et al. [4] reported that treatment with PRID insertion for 10 days beginning on day 21 postpartum allowed the dominant follicle to undergo terminal maturation; ovulation; a normal lifespan and function for the CL; and continued cyclicity in 50 to $60 \%$ of suckled beef cows. Fike et al. [2] showed that a large proportion of suckled beef cows from 25 to 50 days postpartum that were treated with a PRID for 7 days were induced to resume ovarian activity. In our study, 7 out of the 9 cows in Group A, including a cow 13 days postpartum at OPU, were induced to develop new follicles at removal of the PRID and to form corpora lutea by induction of ovulation; furthermore, these seven cows all became pregnant. Ovarian cyclicity does not resume for 35 to 60 days postpartum or 


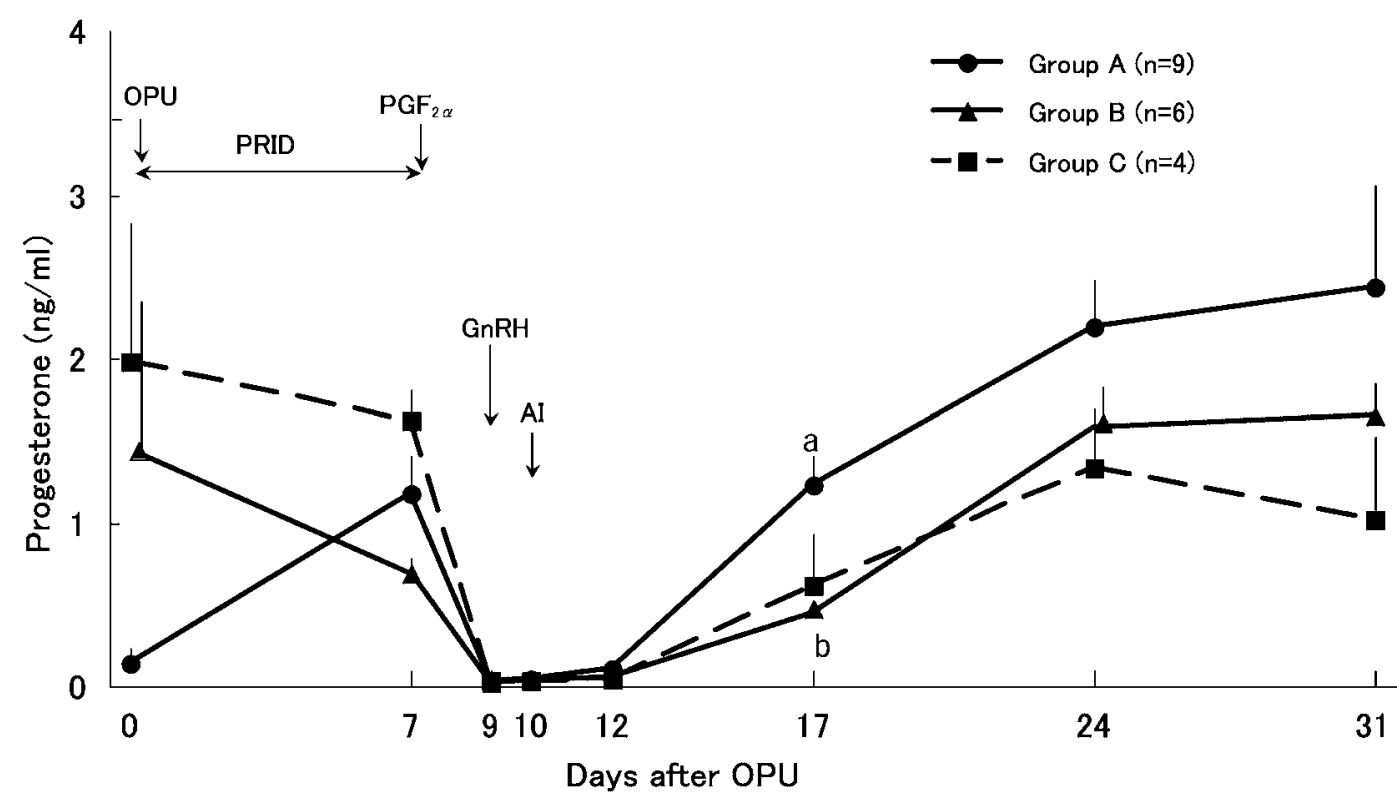

Fig. 2. Profile of the serum progesterone concentrations (means \pm SEM) in the postpartum beef cows treated with a progesterone releasing intravaginal device (PRID)-based timed AI protocol after follicular fluid aspiration using ovum pick-up (OPU). Group A (early postpartum period): cows 13 to 60 days postpartum; Group B (mid postpartum period): cows 61 to 150 days postpartum; Group C (prolonged open period): 151 to 281 days postpartum. Differences between the different letters were significant on Day $17(\mathrm{ab} ; \mathrm{P}<0.01)$.

Table 2. Summary of the ovum pick-up outcome

\begin{tabular}{ccccc}
\hline Group & $\begin{array}{c}\text { Number of aspirated } \\
\left.\text { follicles (Mean } \pm \text { SEM }^{*}\right)\end{array}$ & $\begin{array}{c}\text { Number of retrieved } \\
\text { oocytes (Mean } \pm \text { SEM) }\end{array}$ & Recovery rate (\%) & $\begin{array}{c}\text { Rate of culture- } \\
\text { competent oocytes (\%) }\end{array}$ \\
\hline $\mathrm{A}(\mathrm{n}=9)$ & $14.4 \pm 3.0$ & $12.3 \pm 2.4$ & 85.4 & 41.4 \\
$\mathrm{~B}(\mathrm{n}=6)$ & $14.2 \pm 1.9$ & $15.7 \pm 4.2$ & $110.6^{+}$ & 58.5 \\
$\mathrm{C}(\mathrm{n}=4)$ & $25.5 \pm 4.3$ & $17.5 \pm 4.5$ & 68.6 & 61.4 \\
\hline
\end{tabular}

*: Standard error of the mean.

t: Retrieved oocytes outnumbered aspirated follicles due to the oocytes from small follicles not being detected by ultrasonography.

even longer in suckled beef cows [19]. The results of our study, however, indicate that our protocol can be applied to cows within 60 days postpartum regardless of resumption of ovarian activity at the onset of treatment. In addition, our study demonstrates that pretreatment with OPU does not have an adverse effect on ovulation synchronicity by the PRID treatment and timed AI protocol in early postpartum suckled beef cows. Since OPU synchronizes follicular waves [15-17] and follicular aspiration can skip the follicular regression process to produce emergence of a new wave, OPU at PRID insertion could shorten the period of PRID placement in the vagina and result in better follicular growth synchronization. It is necessary to determine the appropriate length for the PRID placement period from one timed AI protocol to the next to attain a high conception rate because the length is closely related to growth and degeneration of the dominant follicle $[17,20]$. Martinez et al. [17] inserted a controlled internal drug release device (CIDR) intravaginally into beef heifers in conjunction with one of the following at time of CIDR insertion to synchronize follicular wave emergence: intramuscular (im) injection of 5 $\mathrm{mg}$ of estradiol- $17 \beta$ and $100 \mathrm{mg}$ of progesterone $\left(\mathrm{E}_{2} / \mathrm{P}_{4}\right)$; im injection of $100 \mu \mathrm{g}$ of $\mathrm{GnRH}$; or follicular aspiration of all follicles $5 \mathrm{~mm}$ or larger (FA). They 
then injected a luteolytic dose of $\mathrm{PGF}_{2 \alpha}$ and removed the CIDR on days 8,6 , or 5 , in the $E / P$, GnRH and FA groups, respectively, so that the dominant follicle of the induced wave was exposed to exogenous progesterone for a similar period of time in each group. Subsequently, they observed that the onset of follicular growth was delayed in the FA group with CIDR insertion for 5 days and that the size of the dominant follicle at estrus in these animals was smaller than that in the other groups. We inserted the PRID for 7 days and obtained a pregnancy rate of $80 \%(12 / 15)$ in cows that were within 150 days postpartum (Groups A and $B$ ). This result suggests that the length of PRID placement was appropriate for the timed AI protocol applied in our study. Although OPU at the onset of the timed AI protocol may be a rather complicated procedure, it offers promising prospects for contribution to storing of valuable genetic resources by providing ova for in vitro fertilization.

In our study, no significant difference was detected in the OPU outcome among the three groups. This result implies that the timed AI protocol demonstrated in our study has the potential to retrieve specific numbers of culturecompetent oocytes from not only cows during the early postpartum period, but also cows having a prolonged open period whose fertility is relatively low. Walters et al. [21] showed that the numbers of follicles and oocytes retrieved were affected by the number of days postpartum and that conditions related to early lactation have a negative effect on the oocyte quality of dairy cattle. However, oocytes retrieved by OPU from cows 20 to 30 days postpartum have been shown to have growth capacity and fertilizability [22]. Therefore, application of OPU in the timed AI protocol to the cow during the early postpartum period should be an effective method of not only resetting the follicular wave at the onset of treatment and increasing the ovulation synchronization rate, but should also be an effective method of storage of valuable genetic resources to some extent. Particularly, this is the case in regard to Japanese
Black cattle, whose meat value per head is extremely high.

The conception rate of the cows that had peripheral $\mathrm{E}_{2}$ concentrations of $3 \mathrm{pg} / \mathrm{ml}$ or greater at the time of $\mathrm{GnRH}$ injection was $90.9 \%(10 / 11)$, while that in the other cows was $37.5 \%(3 / 8)$. This result indicates that cows to be inseminated must have a follicle that secretes a certain amount of estrogen at the time of $\mathrm{GnRH}$ injection to attain a high conception rate. The average peripheral $\mathrm{E}_{2}$ concentrations of Group A peaked at the time of GnRH injection, and this was also the case in Group B. Moreover, the peripheral progesterone concentrations of Group A were higher than 1.0 $\mathrm{ng} / \mathrm{ml}$ on day 17 . These findings show that suckled beef cows within 60 days postpartum treated by our ovulation synchronization protocol could have a growing mature follicle one day before timed AI, and the CL induced by GnRH could be functional regardless of resumption of ovarian activity at the onset of treatment. The fact that one cow 13 days postpartum at the onset of treatment conceived by the timed AI protocol in our study suggests that this protocol may have a practical advantage in application to suckled beef cows in the very early postpartum period.

Although the reasons why the conception rate was low in Group C are unclear, some reasons may include luteal dysfunction due to anovulation or delayed ovulation.

In conclusion, it is possible to attain a high conception rate in suckled beef cows within 60 days postpartum, regardless of resumption of ovarian activity at the onset of treatment, by applying an ovulation synchronization protocol in combination with the OPU technique on day 0 and PRID placement from day 0 for 7 days.

\section{Acknowledgements}

We are grateful to Dr. G. D. Niswender (Colorado State University, Fort Collins, CO, USA) for providing the antisera to the steroid hormones.

\section{References}

1. Yavas $\mathbf{Y}$, Walton JS. Induction of ovulation in postpartum suckled beef cows: a review.
Theriogenology 2000; 54: 1-23.

2. Fike KE, Day ML, Inskeep EK, Kinder JE, Lewis 
PE, Short RE, Hafs HD. Estrus and luteal function in suckled beef cows that were anestrous when treated with an intravaginal device containing progesterone with or without a subsequent injection of estradiol benzoate. J Anim Sci 1997; 75: 2009-2015.

3. Peters AR. Calving intervals of beef cows treated with either gonadotrophin releasing hormone or a progesterone releasing intravaginal device. Vet Rec 1982; 110: 515-517.

4. Yavas Y, Johnson WH, Walton JS. Modification of follicular dynamics by exogenous FSH and progesterone, and the induction of ovulation using hCG in postpartum beef cows. Theriogenology 1999; 52: 949-963.

5. Ambrose JD, Kastelic JP, Rajamahendran R, Aali M, Dinn N. Progesterone (CIDR)-based timed AI protocols using GnRH, porcine LH or estradiol cypionate for dairy heifers: ovarian and endocrine responses and pregnancy rates. Theriogenology 2005; 64: 1457-1474.

6. Ando T, Kamimura S, Hamana K. Estrous synchronization using an intravaginal progesterone device in combination with $\mathrm{GnRH}$ or estradiol benzoate characterized by the initial ovarian conditions in Japanese Black cows. J Vet Med Sci 2004; 66: 1497-1502.

7. Colazo MG, Kastelic JP, Martinez MF, Whittaker PR, Wilde R, Ambrose JD, Corbett R, Mapletoft RJ. Fertility following fixed-time AI in CIDR-treated beef heifers given GnRH or estradiol cypionate and fed diets supplemented with flax seed or sunflower seed. Theriogenology 2004; 61: 1115-1124.

8. El-Zarkouny SZ, Cartmill JA, Hensley BA, Stevenson JS. Pregnancy in dairy cows after synchronized ovulation regimens with or without presynchronization and progesterone. J Dairy Sci 2004; 87: 1024-1037.

9. Kim IH, Suh GH, Son DS. A progesterone-based timed AI protocol more effectively prevents premature estrus and incomplete luteal regression than an Ovsynch protocol in lactating Holstein cows. Theriogenology 2003; 60: 809-817.

10. Kim UH, Suh GH, Nam HW, Kang HG, Kim IH. Follicular wave emergence, luteal function and synchrony of ovulation following GnRH or estradiol benzoate in a CIDR-treated, lactating Holstein cows. Theriogenology 2005; 63: 260-268.

11. Mialot JP, Constant F, Dezaux P, Grimard B, Deletang F, Ponter AA. Estrus synchronization in beef cows: comparison between GnRH+PGF2 $\alpha+$ GnRH and PRID+PGF2 $\alpha+e C G$. Theriogenology 2003; 60: 319-330.
12. Sakase M, Seo $\mathbf{Y}$, Fukushima $\mathbf{M}$, Noda $\mathbf{M}$, Takeda K, Ueno S, Inaba T, Tamada H, Sawada T, Kawate N. Effect of CIDR-based protocols for timed-AI on the conception rate and ovarian functions of Japanese Black beef cows in the early postpartum period. Theriogenology 2005; 64: 1197-1211.

13. Stevenson JS, Lamb GC, Johnson SK, MedinaBritos MA, Grieger DM, Harmoney KR, Cartmill JA, El-Zarkouny SZ, Dahlen CR, Marple TJ. Supplemental norgestomet, progesterone, or melengestrol acetate increases pregnancy rates in suckled beef cows after timed inseminations. J Anim Sci 2003; 81: 571-586.

14. O'Rourke M, Diskin MG, Sreenan JM, Roche JF. The effect of dose and route of oestradiol benzoate administration on plasma concentrations of oestradiol and FSH in long-term ovariectomised heifers. Anim Reprod Sci 2000; 59: 1-12.

15. Berfelt DR, Lightfoot KC, Adams GP. Ovarian synchronization following ultrasound-guided transvaginal follicle ablation in heifers. Theriogenology 1994; 42: 895-907.

16. Garcia A, Salaheddine M. Effects of repeated ultrasound-guided transvaginal follicular aspiration on bovine oocyte recovery and subsequent follicular development. Theriogenology 1998; 50: 575-585.

17. Martinez MF, Adams GP, Kastelic JP, Bergfel DR, Mapletoft RJ. Induction of follicular wave emergence for estrus synchronization and artificial insemination in heifers. Theriogenology 2000; 54: 757769.

18. Taya K, Watanabe G, Sasamoto S. Radioimmunoassay for progesterone, testosterone and estradiol$17 \beta$ using ${ }^{125}$ I-iodohistamine radioligands. Jpn J Anim Reprod 1985; 31: 186-197.

19. Yavas Y, Walton JS. Postpartum acyclicity in suckled beef cows: A review. Theriogenology 2000; 54: 25-55.

20. Utt MD, Jousan FD, Beal WE. The effects of varying the interval from follicular wave emergence to progestin withdrawal on follicular dynamics and the synchrony of estrus in beef cattle. J Anim Sci 2003; 81: 1562-1567.

21. Walters AH, Bailey TL, Pearson RE, Gwazdauskas FC. Parity-related changes in bovine follicle and oocyte populations, oocyte quality, and hormones to 90 days postpartum. J Dairy Sci 2002; 85: 824-832.

22. Sasamoto $Y$, Sakaguchi M, Nagano M, Katagiri S, Takahashi Y. Follicular development after ovum pick-up and fertilizability of retrieved oocytes in postpartum dairy cattle. Jpn J Vet Res 2004; 51: 151159. 